\section{Publishing and perishing}

SIR - In his article "Publishing and perishing" (Nature 341, 349-350; 1989) John Merriman does a masterly job in describing the serials crisis faced by academic libraries. I dispute, however, his conclusion that commercial publishers are not a major cause of this crisis.

Using figures from Blackwells the subscription agents, he says, "For 1989 over $1988 \ldots$ commercial publishers increased their [journal] subscription prices by 10.57 per cent, the learned societies by 10.40 per cent. Nor are overall prices notably different $-£ 207.50$ for commercial publishers, $£ 217.85$ for learned societies". Yet there is abundant evidence showing that less expensive journals tend to originate with societies rather than commercial publishers. Such findings are based on analysis of price per character, word, 1,000 characters, or other normalized measure, and reveal that in certain subjects, societies and university presses generally publish information at less than commercial companies, and sometimes as little as 5 per cent of commercial prices.

An overview of these studies, which establish a more general pattern, is to be found in the Report of the ARL Serials Prices Project (Association of Research Libraries, Washington, DC, 1989).

DUANE E. WeBster

Association of Research Libraries.

1527 New Hampshire Avenue, NW,

Washington, DC 20036, USA

\section{Citing patents}

SIR-The comments from Frank W. Cousins (Nature 341, 380; 1989) on the necessity of citing patent numbers are useful because the patent literature is important. Each year, more than a million patent publications are produced worldwide. But the patent number is not sufficient in many cases. Many patent offices use the same numerical sequences; many begin a new series each year. A number such as $88 / 1234$ could be a patent number in many different countries. So it is always necessary to add the country code of the issuing patent office. These two-letter codes (for example GB for United Kingdom, US for USA, DE for Bundesrepublik Deutschland, DD for DDR) are concise and are available even for very small countries such as Vanuatu or Tuvalu. The codes are standardized in the international standard ISO 3166 which is frequently updated. They are preferable to automobile country codes (which do not exist for all countries).

Unfortunately, country code plus patent number is still not sufficient for a distinctive citation. The same number is used by many patent offices for various procedural stages (for the same invention). The resulting publications are usually not identical. To give an example: for DE 2338518, three different publications have appeared for the patent specification as filed (open to public inspection, then the examined and accepted specification and the granted patent). To differentiate between them, a document code is necessary which should be added to the number to make it unique (for example DE 2338518-C for the granted version).

A kind of document code nowadays is very often given on the printed specification. There will be a universal standard by WIPO (the World Industrial Property Organization in Geneva). This is especially important if one orders a Japanese publication. The same number (with different kinds of document codes) is used for at least four completely different specifications which do not belong to the same invention.

Patents are not cited very frequently in the journal literature although they may be the only source for technical innovations or at least the earliest one. Many people probably fail to cite them because they do not know how to do so.

A good tool for citing both normal and exotic types of publications is the German standard DIN 1505 part 2 (Zitierregelin; Bibliographic references to documents; rules for citing). Four-and-a-half pages are devoted to patent citations, but there are other examples for citing nearly everything, even a 78 r.p.m. jazz record or something from a museum collection.

MARTINA. LOBECK

Strundenerstrasse 100

D-5000 Köln 80, FRG

\section{Separate culture}

SIR-You are correct (Nature 340, 413; 1989) in saying that the black and coloured people of South Africa "have other things on their minds" than English sports, such as cricket, rugby football and tennis. Their interests are soccer, boxing and athletics, and, for the younger generation, also education, the subject of the Commentary in the same issue of Nature (page 420).

I had the opportunity to see and learn to know South Africa first as an immigrant, later as a citizen and then also from abroad. South African blacks, unlike American blacks, still live in their natural geographical regions and surroundings. They are divided into nine major and several smaller tribes, each with its own culture, tradition, habits and language. These circumstances are usually unknown to, or ignored by, foreigners to South Africa.

For at least 80 per cent of all black scholars, first contact with the English and Afrikaans languages (the languages of instruction) is at school. Separate school education, at least at primary level, is thus necessary. That is a cultural issue, not a political issue stemming from apartheid.

Because of the increase in the black population, more schools have to be built in these geographical regions. Black students cannot attend white schools, which may be more than walking distance away, so that schools have to be brought to the scholars because of the lack of transport systems. And transport systems cannot be created from taxes, paid by the already heavily burdened small percentage of taxpayers.

As to higher education, any student with the necessary exemptions in the matriculation examinations has the opportunity to enrol for higher education. As correctly mentioned in the two Nature articles, enrolment is possible at any university. The reasons for the low proportions of black students thus have to be found elsewhere, and are not political. South Africa is concerned about the figures, but is not the only one thus affected. Similar figures for black student enrolment apply in the United States (Science 244, 1536; 1989).

G. OSTHOFF

Department of Biochemistry,

Bowman Gray School of Medicine,

Wake Forest University,

Winston Salem,

North Carolina 27103, USA

\section{Brazilian research}

SIR-In your extensive review of science in Brazil (Nature 342, 353-374; 1989), we find it most surprising that so little mention is made of the distinguished research on tropical diseases there, other than that at the Instituto Oswaldo Cruz in Rio de Janeiro. Two laboratories with considerable international reputations in this field are the Instituto René Rachou in Belo Horizonte, notable particularly for its contributions to schistosomiasis and malaria, and the Instituto Evandro Chagas (IEC) in Belém for its work on malaria, leishmaniasis, hepatitis and diarrhoeal diseases.

At the IEC, important studies on arthropod-borne viruses were carried out in the 1950s and 1960s, with Rockefeller Foundation support; more recently, there has been remarkable work there on the epidemiology of leishmaniasis of the Amazon region by Ralph Lainson, Jeffrey Shaw and their colleagues, generously supported by the Wellcome Trust for the past 20 years.

Department of Genetics,

DAVID WALLIKER

University of Edinburgh,

Edinburgh EH9 3JN, UK

London School of Hygiene

GEOFFREY TARGETT

and Tropical Medicine,

London WC1 7HT, UK 